\title{
Perception of Interventional Radiology among Jazan Medical Students: Assessment of Knowledge and Career Intentions
}

\author{
${ }^{1}$ Department of Radiology, General Hospital, Jazan, Saudi Arabia \\ 2Jazan University, Jazan, Saudi Arabia \\ ${ }^{3}$ Department of Radiology, King Fahad Central Hospital, Jazan, \\ Saudi Arabia
}

Salha Al Bahkali ${ }^{1} \quad$ Ali Al Harbi ${ }^{2} \quad$ Fatimah Kamili $\quad$ Ibrahim Al Rashidi ${ }^{1}$

Address for correspondence Salha M. Bahkali, MD, Department of radiology, General Hospital, Jazan, Saudi Arabia (e-mail: salhabahkali1@gmail.com).

Arab J Intervent Radiol 2021;5:16-24.

\begin{abstract}
Context Lack of awareness among the students in the medical field is the greatest challenge to overcome in the emergence of contemporary interventional radiology (IR). Objectives We aimed to conduct a survey among medical students of Jazan University to explore their knowledge about IR, interest in IR as a future career, and preferred methods of training in IR.

Materials and Methods This was a cross-sectional, self-directed questionnaire study. The target population was all medical students at Jazan University. Surveys were sent to 600 students. The questionnaire consisted of 11 closed and open-ended questions. Statistical Analysis We calculated the size of the sample using the Raosoft Sample Size Calculator Web site. Data analysis was performed using SPSS statistics.

Results A total of 270 students responded (45\%); more than half of the respondents $(58.5 \%)$ were in the preclinical stage, while the rest were in the clinical stage. About $62.5 \%$ of clinical students and $66.4 \%$ preclinical students reported that their perception regarding the terminology of IR was good or excellent. Regarding the identification of interventional radiologists, 50.9\% from the clinical students thought them to be radiologists and $50 \%$ from preclinical students also identified them as such.

About $29.5 \%$ from the clinical students and $27.8 \%$ from the preclinical students thought them special surgeons, and $31.3 \%$ clinical students compared with $30.4 \%$ preclinical students believed they are vascular surgeons working with X-rays. About $19.6 \%$ clinical students compared with $17.7 \%$ preclinical students said they are general surgeons

Keywords

- awareness

- interventional radiology

- medical students

- Jazan working with X-rays, and $48.2 \%$ clinical students compared with $45.6 \%$ preclinical students said they are special radiologists who work with percutaneous techniques. There was a significant difference $(p=0.041)$ in the responses between preclinical and clinical students regarding knowledge about what this medical specialty does. About $60.8 \%$ of clinical students reported that their knowledge and information regarding IR are efficient in comparison to $39.2 \%$ of preclinical students.
\end{abstract}

published online June 4, 2021
DOI https://doi.org/

$10.1055 / \mathrm{s}-0041-1730118$ ISSN 2542-7075 (c) 2021. The Pan Arab Interventional Radiology Society

This is an open access article published by Thieme under the terms of the Creative Commons Attribution-NonDerivative-NonCommercial-License, permitting copying and reproduction so long as the original work is given appropriate credit. Contents may not be used for commercial purposes, or adapted, remixed, transformed or built upon. (https://creativecommons.org/licenses/by-nc-nd/4.0/).

Thieme Medical and Scientific Publishers Private Ltd. A-12, Second Floor, Sector -2, NOIDA -201301, India 
Conclusion This study demonstrated that the basic knowledge among Jazan medical students is poor. About half of the respondents were clinical students who understood the radiology specialty, compared with one-third of preclinical students. This could impact the student's decision toward IR as a future career.

\section{Introduction}

Interventional radiology (IR) is a medical specialty that has experienced an extraordinary growth in recent years. However, there is a lack of visibility in the health administration and the university community, especially among medical students. ${ }^{1}$ Limited awareness and exposure to IR among medical students have been reported by several studies from different parts of the world. ${ }^{2-5}$ For example, a Spanish study involving 313 participants revealed that medical students had poor knowledge of IR. ${ }^{1}$ Previous research has displayed the importance of organized exposure to IR during medical education, and has signified the paucity of mandatory core clerkships in IR and diagnostic radiology. ${ }^{6-8}$ In addition, several studies have illustrated that a structured undergraduate IR curriculum improved medical students' knowledge and regard of the specialty. ${ }^{9-11}$ In relation to Saudi medical students, we found four studies, one of them being a large study from Riyadh ${ }^{12}$ and northwestern ${ }^{13}$ and southwestern Saudi Arabia $^{14,15}$ that unanimously reported poor knowledge and exposure to IR. Thus, we aimed to conduct this survey among Saudi medical students of Jazan University to explore the extent of their knowledge about IR, their interests in IR as a future career, and their preferred methods of learning about IR. The most important goal of this study is to engage medical students' attention and make them focus on IR, particularly a real-world understanding of their limitations, which must be improved due to the importance of this information in their professional life. This study aims to assess the knowledge gap and provide better guidance for future research investigating the knowledge about IR among medical students in Saudi Arabia.

\section{Materials and Methods}

An observational cross-sectional study was conducted at the Faculty of Medicine at Jazan University, which is enrolled with $\sim 600$ medical students. A random sample size of 235 medical students with a 95\% confidence interval was calculated online through the Raosoft Sample Size Calculator and was stratified according to gender and year of study. A formal ethical approval was received from the university's ethical committee. The questionnaire was distributed among 600 medical students, among which 270 medical students (45\%) completed the questionnaire and built our study cohort. Participants were asked to fill out an 11-point paper-based questionnaire formulated to assess their knowledge about IR. The survey questions were adapted with permission from a previous study, ${ }^{1}$ a validated questionnaire whose objectives and questions match our project. The survey questions covered some demographic characteristics (gender, year of study, etc.) in addition to 11 questions about IR, preferred methods for learning about IR, and interest in IR as a future career (assessed by the 10th and 11th questions). They are increasing the motivation to learn this subject as a distinct curriculum to be taught in medical school. The survey was pretested to assess its readability and reliability by the authors. The survey was distributed on paper for a 1-month period from March 1st to March 30th, 2020. Details of names and contact details were kept confidential. Verbal informed consent was received, and participation was completely voluntarily.

Inclusion Criteria:

1. Medical students at Jazan University.

2. Students willing to participate in the survey.

\section{Exclusion Criteria:}

1. Incomplete and partially answered surveys.

2. Answered by different university students.

\section{Statistical Analysis Used}

All the data were transferred from the paper surveys to the Microsoft Excel Spreadsheet software for data management, and then all statistical analyses were performed using the $\mathrm{R}$ development environment (RStudio Version 1.3.959) on a Linux machine. Categorical variables were presented as frequencies and percentages. A comparison between categorical variables was performed using the chi-squared test or Fisher's exact test. Differences would be considered statistically significant if $p<0.05$.

\section{Results}

Two-hundred seventy observations out of potential 600 students (45\%) were able to turn in the survey where more than one half of them (58.5\%) were in the preclinical stage, while the rest were in the clinical years. The preclinical years are the second $(18.93 \%)$ and third $(18.61 \%)$ years of medical study at Jazan University, while clinical years refer to those in the 4th (23.97\%), 5th (19.65\%), and 6th (18.93\%) years of study. - Fig. 1 presents the gender distribution of the participants as follows: 81 (30\%) were females and 189 (70\%) were males. This skewed distribution was due to the survey being mainly distributed among the male students, but the male to female ratio at the university is approximately the same. Sixty-four $(23.7 \%)$ of the participants were from the second year, 54 (20\%) were from the third year, and $40(14.8 \%)$ were from the fourth year, with a total of 158 participants 


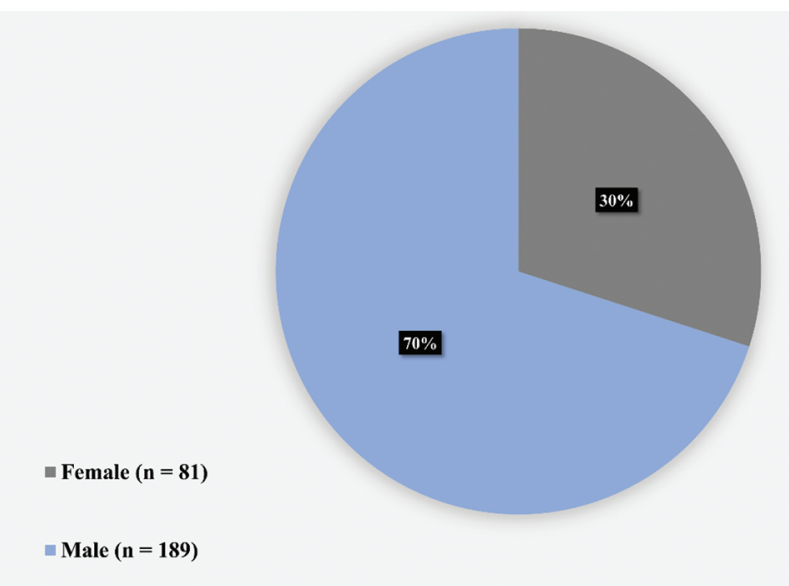

Fig. 1 Distribution of sample according to gender (female $30 \%$; male $70 \%$.

(58.5\%) in their preclinical years. Fifty-seven $(21.1 \%)$ were from the fifth year, 55 (20.4\%) were from the sixth year, with a total of 112 participants (41.5\%) in their clinical years.

However, the majority of the students reported that their knowledge and information about IR were poor. The participants' knowledge of the surgical procedures associated with the name of the medical activity is demonstrated in - Tables 1 and 2; 62.5\% from clinical students in compared with $66.4 \%$ from preclinical students identified the IR, and $12.5 \%$ from clinical students compared with $15.2 \%$ from preclinical students identified the interventionalism, $43.8 \%$ from clinical students in comparison to $46.8 \%$ from preclinical students recognized image-guided minimally invasive surgery, then $43.8 \%$ from clinical students compared with $53.2 \%$ from preclinical students identified percutaneous surgery, and 66\% from clinical students while 63.9\% from preclinical students recognized the vascular and IR. The participants' knowledge of the actual identity of interventional radiologists is illustrated in - Tables $\mathbf{3}$ and $\mathbf{4}, \mathbf{5 0 . 9 \%}$ from clinical students in comparison to $50 \%$ from preclinical students' said they are radiologists, $29.5 \%$ from clinical students while $27.8 \%$ from preclinical students said they are special surgeons, 31.3\% from clinical compared with $30.4 \%$ from preclinical students said they are vascular surgeons working with X-rays, $19.6 \%$ from clinical students compared with $17.7 \%$ from preclinical students said they are general surgeons working with X-rays, and $48.2 \%$ from clinical

Table 1 Clinical year students-do you know any of the following names associated with this medical activity?

\begin{tabular}{|l|l|l|l|}
\hline $\begin{array}{l}\text { Interventional radiology } \\
\text { terminology }\end{array}$ & Yes & No & $\begin{array}{l}\text { Don't } \\
\text { know }\end{array}$ \\
\hline Interventional radiology & 62.5 & 23.2 & 14.3 \\
\hline Interventionalism & 12.5 & 53.6 & 33.9 \\
\hline Image-guided minimally invasive surgery & 43.8 & 33 & 23.2 \\
\hline $\begin{array}{l}\text { Percutaneous surgery-vascular and } \\
\text { interventional radiology }\end{array}$ & 43.8 & 29.4 & 26.8 \\
\hline Vascular and interventional radiology & 66 & 17 & 17 \\
\hline
\end{tabular}

years compared with $45.6 \%$ from the preclinical years said they are special radiologists who work with percutaneous techniques. Besides, the participants' thoughts about how those training for IR be trained were displayed through the $\boldsymbol{-}$ Figs. $\mathbf{3 A}$ and $\mathbf{B}$, and the $24.1 \%$ from clinical students

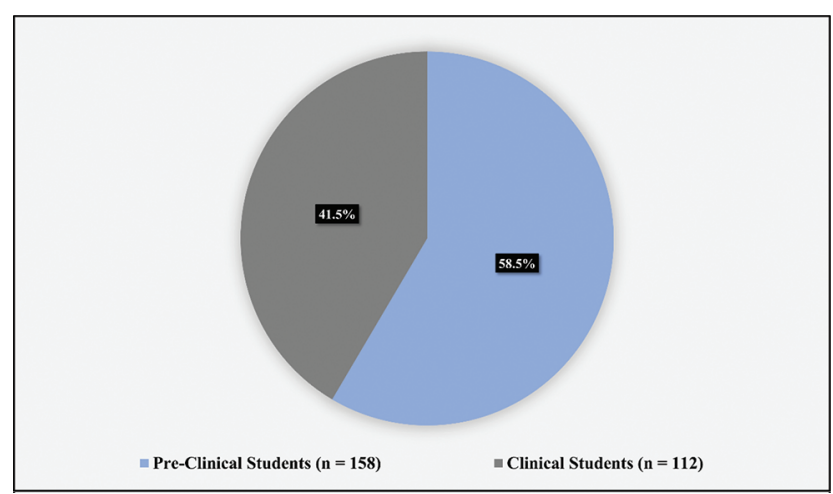

Fig. 2 Participants current study years in medical college.

Table 2 Preclinical year students-do you know any of the following names associated with this medical activity?

\begin{tabular}{|l|l|l|l|}
\hline $\begin{array}{l}\text { Interventional radiology } \\
\text { terminology }\end{array}$ & Yes & No & $\begin{array}{l}\text { Don't } \\
\text { know }\end{array}$ \\
\hline Interventional radiology & 66.4 & 18.3 & 13.3 \\
\hline Interventionalism & 15.2 & 60.8 & 24 \\
\hline $\begin{array}{l}\text { Image-guided minimally invasive } \\
\text { surgery }\end{array}$ & 46.8 & 38 & 15.2 \\
\hline $\begin{array}{l}\text { Percutaneous surgery-vascular and } \\
\text { interventional radiology }\end{array}$ & 53.2 & 30.3 & 16.5 \\
\hline Vascular and interventional radiology & 63.9 & 22.8 & 13.3 \\
\hline
\end{tabular}

Table 3 Clinical year students-do you know who interventional radiologists are?

\begin{tabular}{|l|l|l|l|}
\hline & Yes & No & $\begin{array}{l}\text { Don't } \\
\text { know }\end{array}$ \\
\hline Radiologists & 50.9 & 16.1 & 33 \\
\hline Special surgeons & 29.5 & 24.1 & 46.4 \\
\hline Vascular surgeons working with X-rays & 31.3 & 18.7 & 50 \\
\hline General surgeons working with X-rays & 19.6 & 26.8 & 53.6 \\
\hline $\begin{array}{l}\text { Special radiologists who work with } \\
\text { percutaneous techniques }\end{array}$ & 48.2 & 14.3 & 37.5 \\
\hline
\end{tabular}

Table 4 Preclinical year students-do you know who interventional radiologists are?

\begin{tabular}{|l|l|l|l|}
\hline & Yes & No & Don't know \\
\hline Radiologists & 50 & 15.2 & 34.8 \\
\hline Special surgeons & 27.8 & 22.2 & 50 \\
\hline $\begin{array}{l}\text { Vascular surgeons working } \\
\text { with X-rays }\end{array}$ & 30.4 & 19.6 & 50 \\
\hline $\begin{array}{l}\text { General surgeons working } \\
\text { with X-rays }\end{array}$ & 17.7 & 26.6 & 55.7 \\
\hline $\begin{array}{l}\text { Special radiologists who } \\
\text { work with percutaneous } \\
\text { techniques }\end{array}$ & 45.6 & 16.5 & 38 \\
\hline
\end{tabular}


in comparison to $22.2 \%$ from preclinical students thought they should be trained as surgeons, and $43.6 \%$ from clinical students and $45.6 \%$ from preclinical students thought they should be trained as radiologists. The participants' knowledge of which procedures are routinely performed by interventional radiologists from the clinical students' comparison to preclinical students' responses are shown in -Figs. $4 \mathrm{~A}$ and B that are as follows: $41.1 \%$ from clinical students and $41.8 \%$ from preclinical students identified percutaneous transluminal coronary angioplasty, while $26.8 \%$ from clinical students compared with $18.4 \%$ from preclinical students identified aorto-bifemoral bypass, then $21.4 \%$ from clinical students compared with $24.7 \%$ from preclinical students identified hemodialysis arteriovenous fistulas, and $27.7 \%$ from clinical students compared with $22.2 \%$ from preclinical students identified central venous accesses. Besides, the participants' thoughts about which procedures are usually performed by interventional radiologists are demonstrated in - Figs. $\mathbf{5 A}$ and $\mathbf{B}$, and the $18.8 \%$ clinical students in comparison to $10.1 \%$ preclinical students were identified vertebroplasty, $33.9 \%$ from clinical students compared with $32.9 \%$ from preclinical students identified tumoral radiofrequency ablation, 33\% from clinical students compared with $21.5 \%$ from preclinical students identified endovascular aneurysm repair treatment of abdominal aortic aneurysm, $18.8 \%$ from clinical students compared with $24.7 \%$ from preclinical students identified percutaneous nephrostomy, and 25\% from clinical students compared with $48.1 \%$ identified image-guided core biopsy. Regarding the participants' ideas about who usually performs percutaneous transluminal angioplasty, 43.8\% from the clinical students and $39.9 \%$ from preclinical students' responses are denoted in -Figs. $\mathbf{6 A}$ and $\mathbf{B}$; $43.8 \%$ from clinical students compared with $39.9 \%$ from preclinical students recognized interventional cardiologists, $33.9 \%$ from clinical students compared with $26.6 \%$ from preclinical students recognized vascular surgeons, $43.8 \%$ from clinical students compared with $39.2 \%$ from preclinical students recognized interventional radiologists, and $8.9 \%$ from clinical students compared with $8.9 \%$ from preclinical students recognized others. They exhibited their thoughts about what IR requires,
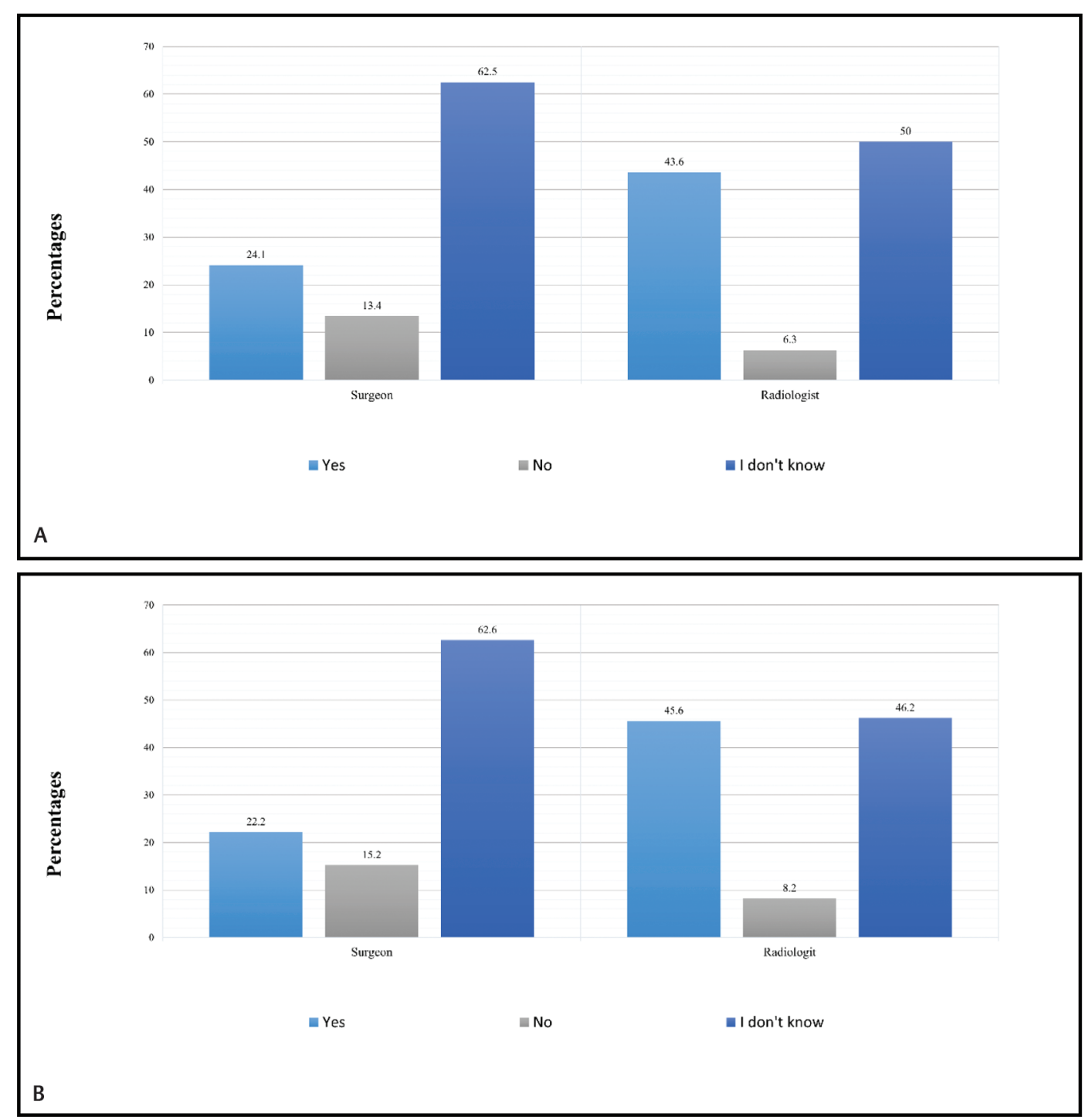

Fig. 3 (A) Clinical year students-what should be the training of an interventional radiologists? (B) Preclinical year students-what should be the training of an interventional radiologists? 

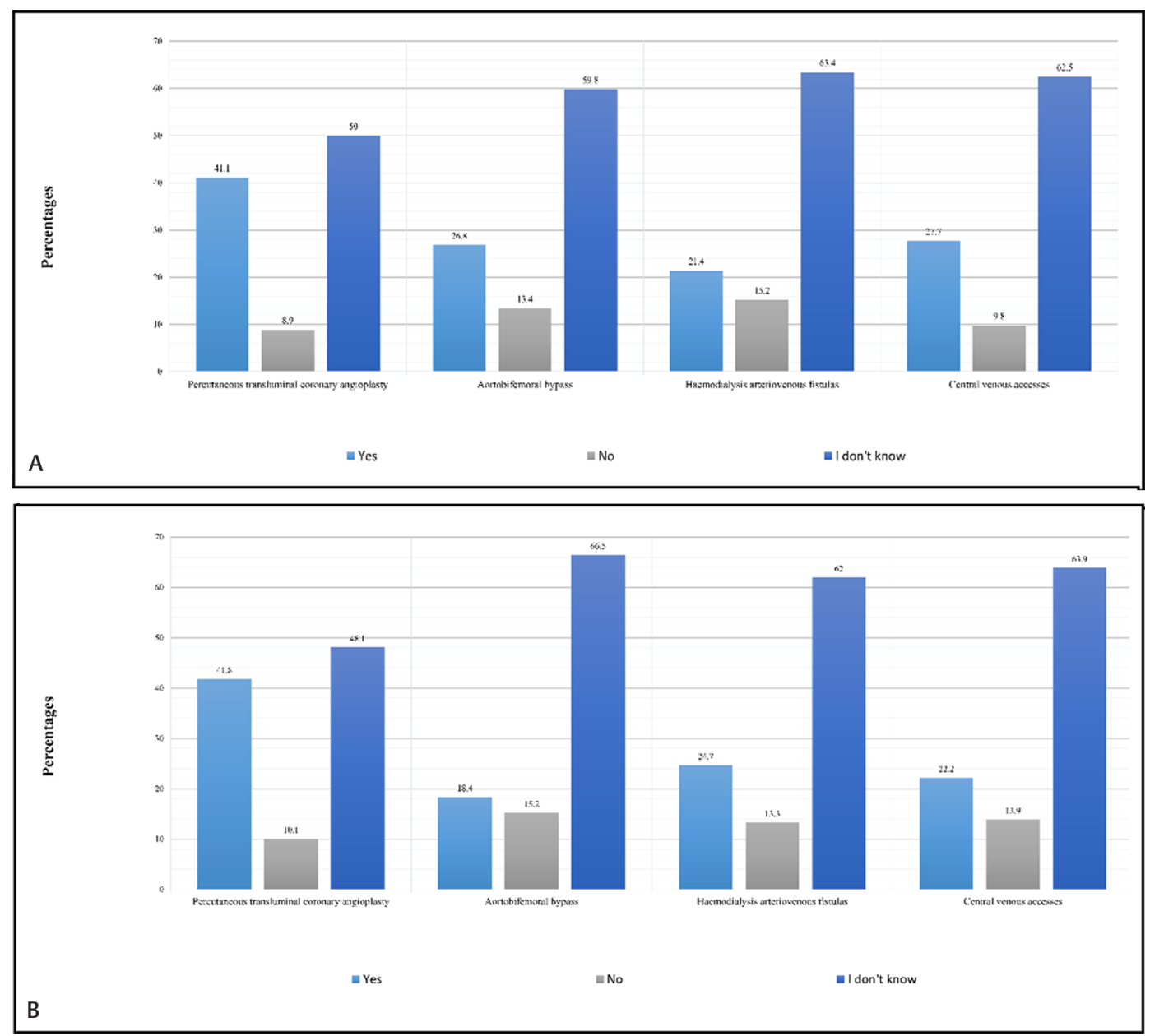

Fig. 4 (A) Clinical year students-do you know which of these procedures are routinely performed by an interventional radiologist? (B) Preclinical year students-do you know which of the following procedures are usually done by interventional radiologists?

as shown in - Figs. $7 \mathbf{A}$ and $\mathbf{B}$, and $29.5 \%$ from clinical students compared with $31 \%$ from preclinical students thought interventional radiologists must have outpatient services, and $42 \%$ from clinical students compared with $39.2 \%$ from preclinical students believed that interventional radiologists must have patient admitting privileges.

- Table 5 displayed a comparison between preclinical and clinical students. There was a significant difference $(p=$ 0.041 ) in the responses between preclinical and clinical students regarding knowledge about if they do know what this medical specialty does $(60.8 \%$ of clinical students said yes vs. $39.2 \%$ of preclinical students). No significant difference was present between clinical and preclinical students in quantifying knowledge about IR ( $p=0.178$ ), desire to know more about IR ( $p=0.315)$, and desire to have this subject taught during undergraduate medical training $(p=0.959)$.

\section{Discussion}

Unfortunately, the IR specialty is not common in many regions worldwide, and thus there is a considerable scarcity of IR specialists. A scant proportion of professional interventional radiologists are tasked with serving a large population of patients in need of their services. The 2016 United
Kingdom workforce report on clinical radiology showed that the radiology workforce was not growing quickly enough to meet the boundless demand in this clinical field. There was minimal enrolment in the universities, which was attributed to the absence of clear information and familiarity with the IR specialty among the medical undergraduates, who will fill future clinical jobs. Dismally, there is insufficient literature available on the understanding of the IR field among the medical students in the region. This lack of concrete information acts as a hindrance to embracing IR and seems to promote the reasoning that IR is a minor subject in medicine. ${ }^{15}$

Moreover, there are negative misconceptions about specializing in IR as a career path. One predominant misunderstanding about IR is that there is a lack of interpersonal contact between the patient and the nurse, leading radiology to be seen as a subject that simply involves reading and interpreting scan images. This research is connected to a previous study performed in the United States that signified the absence of interpersonal patient contact, the work atmosphere, and the level of influence on the patient as primary explanations of why students do not pursue a radiology career. Significant improvement in information dissemination to medical students in the early stages can inspire and enhance enrollment in a radiological specialty. ${ }^{16}$ According 


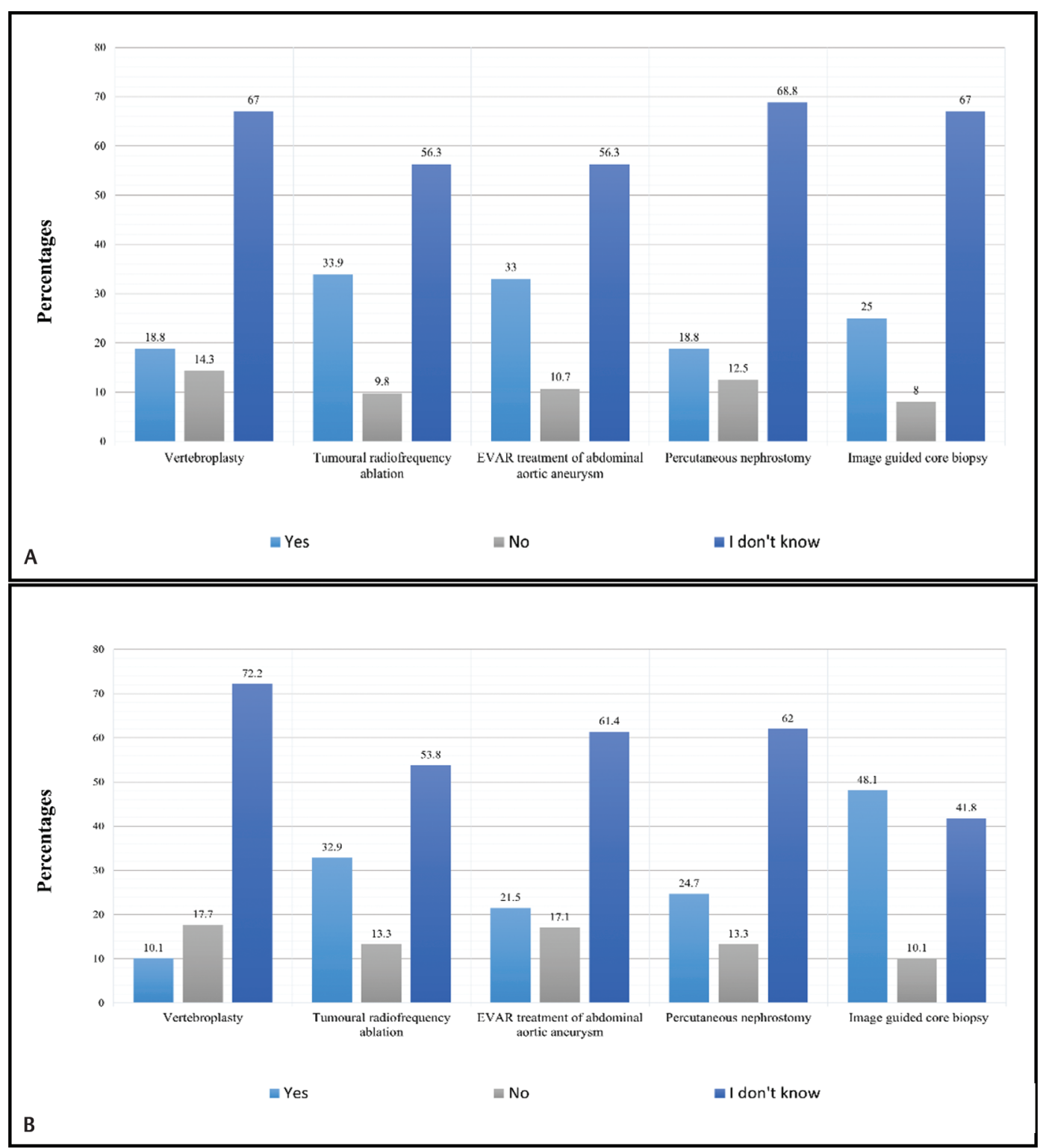

Fig. 5 (A) Clinical year students-do you know which of the procedures are usually done by interventional radiologists? (B) Preclinical year students-do you know which of the procedures are usually done by interventional radiologists?

to our research, preclinical participants presented more knowledge of radiology-related terms than clinical participants. These results identified a more considerate outcome of the theoretical understanding of radiology being higher in preclinical participants than in clinical participants. For example, in identifying IR and interventionalists, a strong understanding of the knowledge was identified in preclinical students (66.4 and $15.2 \%$, which symbolizes the understanding of IR and interventionalists, compared with $62.5 \%$ and $12.5 \%$ among clinical students). At 66\%, clinical students had more knowledge of vascular and IR than preclinical students (63.9\%), which identified an increase in the knowledge among the participants.

In evaluating the student's understanding of the term "radiologist," there were few discrepancies, with overall results almost the same for both clinical and preclinical participants. A total of $24.1 \%$ of clinical students thought IR training was for surgeons only, while $45 \%$ suggested radiologists. Regarding routine activities performed by a radiologist, clinical students had more plentiful knowledge of the subject matter than preclinical students. Overall, the study showed substantial differences ( $p=0.041)$ between preclinical and clinical participants. A majority (60.8\%) of clinical students understood the radiology specialty compared with preclinical students (39.2\%). Medical students' knowledge and interest in IR in the undergraduate curriculum are inadequate. This could influence a student's decision regarding IR as a career. An undersized difference was noted in the possession of quantifiable information on the IR field between the two students in different phases of training. Therefore, the research calls for a definite need to encourage the adoption of IR in medical studies curricula. 


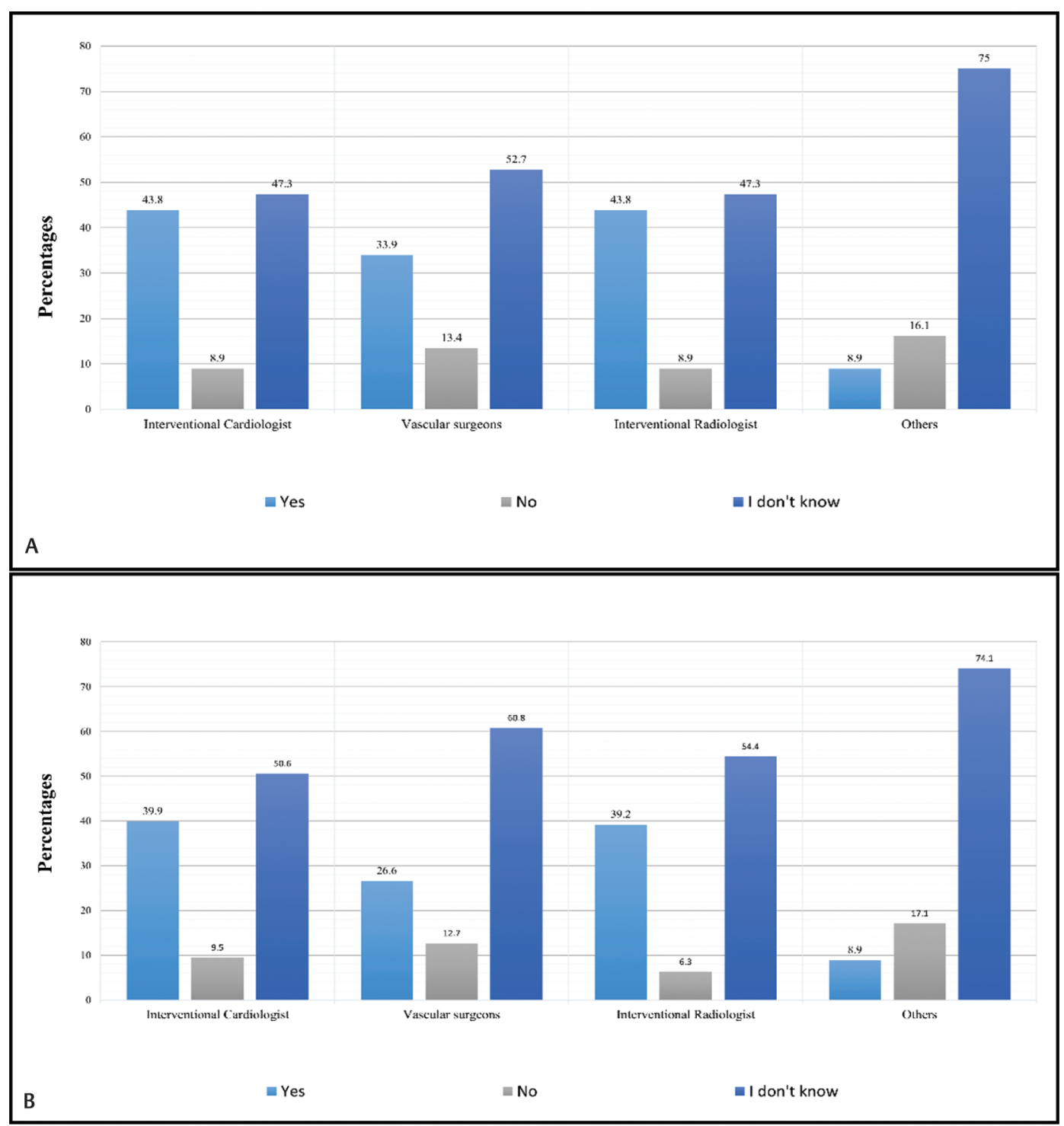

Fig. 6 (A) Clinical year students-who usually performs percutaneous transluminal angioplasty? (B) Preclinical year students-who usually performs percutaneous transluminal angioplasty?

Table 5 Comparison of responses between preclinical and clinical students

\begin{tabular}{|c|c|c|}
\hline Question & Preclinical students & Clinical students \\
\hline Do you know what this medical specialty does? & \multicolumn{2}{|l|}{$p=0.041$} \\
\hline ( & $96(60.8 \%)$ & $54(48.2 \%)$ \\
\hline No & $62(39.2 \%)$ & $58(51.8 \%)$ \\
\hline Rate your knowledge about this medical specialty. & \multicolumn{2}{|l|}{$p=0.178$} \\
\hline Excellent & $18(11.4 \%)$ & $12(10.7 \%)$ \\
\hline Good & $32(20.3 \%)$ & $12(10.7 \%)$ \\
\hline Adequate & $37(23.4 \%)$ & $27(24.1 \%)$ \\
\hline Poor & $71(44.9 \%)$ & $61(54.5 \%)$ \\
\hline Would you like to know more about interventional radiology? & \multicolumn{2}{|l|}{$p=0.315$} \\
\hline Yes & $109(69 \%)$ & $86(76.8 \%)$ \\
\hline No & $21(13.3 \%)$ & $13(11.6 \%)$ \\
\hline I don't know & $28(17.7 \%)$ & $13(11.6 \%)$ \\
\hline Would you like this subject taught during your medical undergraduate training? & \multicolumn{2}{|l|}{$p=0.959$} \\
\hline Strongly agree & $49(31 \%)$ & $35(31.3 \%)$ \\
\hline Agree & $42(26.6 \%)$ & $32(28.6 \%)$ \\
\hline Neither agree nor disagree & $58(36.7 \%)$ & $40(35.7 \%)$ \\
\hline Disagree & $9(5.7 \%)$ & $5(4.5 \%)$ \\
\hline
\end{tabular}




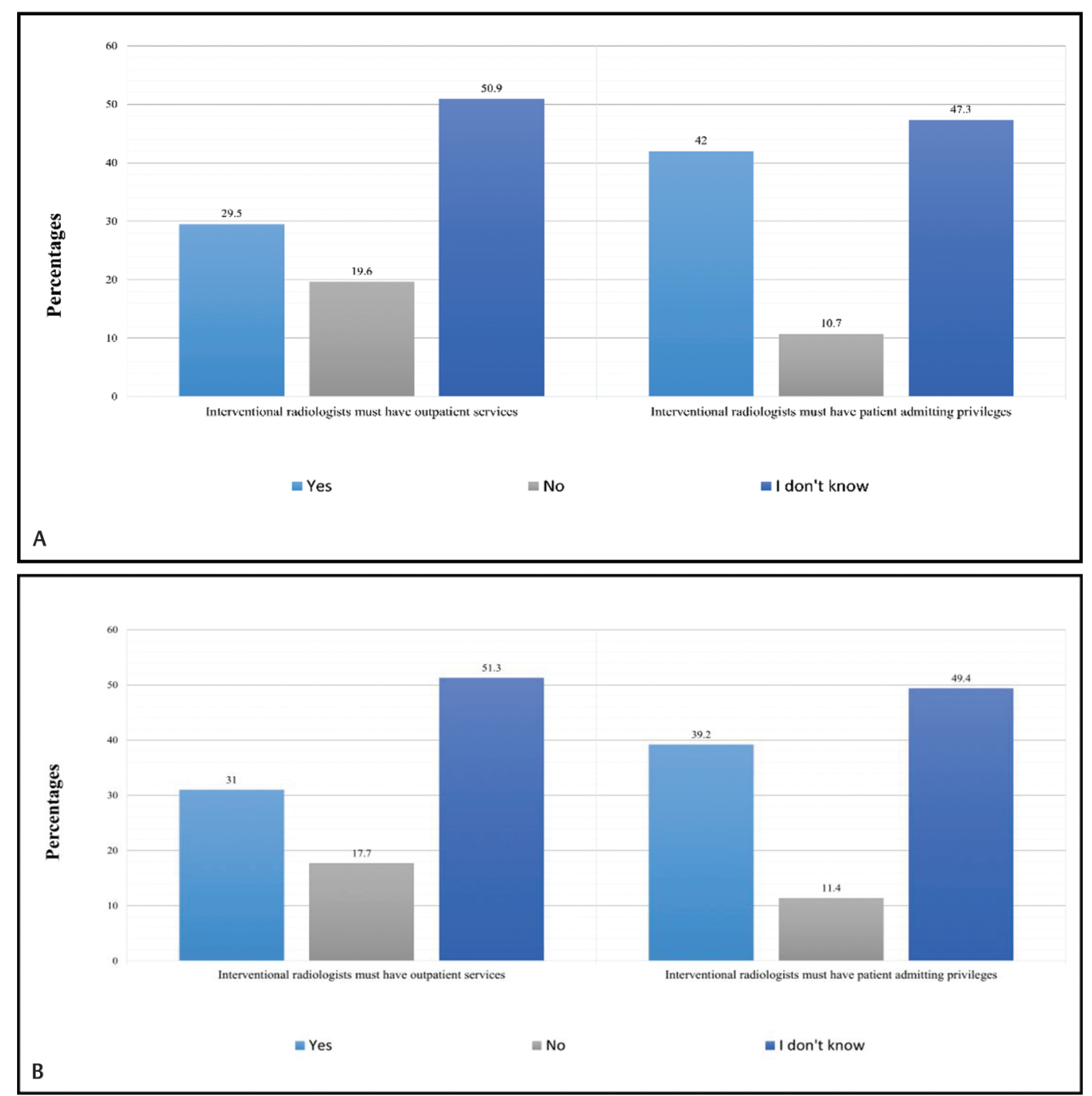

Fig. 7 (A) Clinical year students-in relation to interventional radiology, do you think that interventional radiology requires? (B) Preclinical year students-in relation to interventional radiology, do you think that interventional radiology requires?

The absence of knowledge and passion poses a significant challenge to the development of medical technology. Although the study focused on only one medical institution, Saudi Arabia lacks a well-structured IR program at the university level. This problem can be solved by direct assistance from interventional radiologists in developing an undergraduate radiology curriculum. Many methods might be used to encourage medical students into the IR field, including an incorporated learning system for preclerkship students, IR physicians serving as tutors via dedicated courses, mandatory rotations, and electives during their internship or their summer training. The lack of an integrated radiology curriculum including IR in medical schools across the country should be addressed to the Council of Deans of the Saudi Medical Schools. Also, the contribution of the Saudi Interventional Radiology Society and Pan Arab of Interventional Radiology Society will be important when addressing this problem.

\section{Conclusion}

This study demonstrated that the basic knowledge and interest in IR in the undergraduate curriculum among Jazan medical students are poor. About half of the respondents were in the clinical stage who understood the radiology specialty, while one third were in the preclinical stage. This could impact the student's decision toward IR as a future career.

\section{Financial Support and Sponsorship}

Nil.

\section{Conflict of Interest}

There are no conflicts of interest. 


\section{References}

1 de Gregorio MA, Guirola JA, Sierre S, Serrano-Casorran C, Gimeno MJ, Urbano J. Interventional radiology and Spanish medical students: a survey of knowledge and interests in preclinical and clinical courses. Cardiovasc Intervent Radiol 2018;41(10):1590-1598

2 Nissim L, Krupinski E, Hunter T, Taljanovic M. Exposure to, understanding of, and interest in interventional radiology in American medical students. Acad Radiol 2013;20(4):493-499

3 Wang ZX, Shan T. Awareness of interventional radiology before professional training and outcome measurement of an interventional radiology curriculum: a survey of third-year undergraduates in a Chinese medical college. Diagn Interv Radiol 2019;25(5):375-379

4 Bassuner J, Duncan D, Molloy C, et al. Recruiting medical students to interventional radiology: current state of affairs. Acad Radiol 2019;26(9):1274-1277

5 Straus CM, Webb EM, Kondo KL, et al. Medical student radiology education: summary and recommendations from a national survey of medical school and radiology department leadership. J Am Coll Radiol 2014;11(6):606-610

6 Goldman DT, Magnowski A, Rochon PJ, et al. The state of medical student teaching of interventional radiology: implications for the future. J Am Coll Radiol 2018;15(12):1761-1764

7 Branstetter BF IV, Faix LE, Humphrey AL, Schumann JB. Preclinical medical student training in radiology: the effect of early exposure. AJR Am J Roentgenol 2007;188(1):W9-14

8 Arleo EK, Bluth E, Francavilla M, Straus CM, Reddy S, Recht M. Surveying fourth-year medical students regarding the choice of diagnostic radiology as a specialty. J Am Coll Radiol 2016;13(2):188-195
9 Shaikh M, Shaygi B, Asadi H, et al. The introduction of an undergraduate interventional radiology (IR) curriculum: impact on medical student knowledge and interest in IR. Cardiovasc Intervent Radiol 2016;39(4):514-521

10 O'Malley L, Athreya S. Awareness and level of knowledge of interventional radiology among medical students at a Canadian institution. Acad Radiol 2012;19(7):894-901

11 Ghatan CE, Kuo WT, Hofmann LV, Kothary N. Making the case for early medical student education in interventional radiology: a survey of 2nd-year students in a single U.S. institution. J Vasc Interv Radiol 2010;21(4):549-553

12 Abohimed AB, Al Zahrani Y, Arabi M. Interventional radiology awareness among the final-year medical students in Riyadh. Arab J Intervent Radiol 2020;4:32-37

13 Albaqawi R, Alreshidi M, Alshubrami D, Alrasheedi H, Alreshidi F, Alrashidi I. Awareness of interventional radiology among clinical years' medical students and medical interns at University of Hail. Arab J Interv Radiol 2019;3:58

14 Alshumrani GA. Awareness of interventional radiology among final-year medical students and medical interns at a university in Southwestern Saudi Arabia. Saudi Med J 2013;34(8):841-847

15 Alnajjar SF, Alshamrani HM, Banasser AM, Alshehri HZ, Wazzan MA, Abduljabbar AH. Awareness of interventional radiology among medical students at a Saudi Medical School: clerkship versus pre-clerkship years. Oman Med J 2019;34(5):420-426

16 Lee AM, Lee MJ. Teaching IR to medical students: a call to action. Cardiovasc Intervent Radiol 2018;41(2):203-205 